\title{
SISTEM INFORMASI RESERVASI RESTORAN
}

\author{
Mochamad Fajar Wicaksono $^{1}$, Intan Kurniawati Hamsir ${ }^{2}$ \\ Teknik Komputer UNIKOM ${ }^{1,2}$ \\ mfajarwicaksono@gmail.com ${ }^{1}$, intankurniawatihamsir@gmail.com²
}

\begin{abstract}
Restaurant reservations generally take place by telephone. Reservations are usually only ordering table numbers. Consumers cannot order food at that time because they don't see a menu list. The purpose of this study was to build a restaurant reservation system based on the mini pc raspberry pi. The system approach methodology used is structured. The method of developing the system with the waterfall and the tools in the form of context diagrams and DFD. The results of this study are raspberry pi mini pc based restaurant reservation system that can be accessed by consumers through the Android application. Consumers will be able to make food reservations and reservations through the android application. In the application, consumers can see what menus are available in the restaurant. The consumer will get a Barcode as proof of reservation. When the consumer arrives, he simply shows the Barcode he has and the order will be processed immediately. This will shorten consumers' time waiting for food orders to be served.
\end{abstract}

Keywords : Reservation, Restaurant reservation, Barcode, Raspberry pi, Android

\section{PENDAHULUAN}

Reservasi restoran yang umumnya berjalan ialah melalui telepon. Namun, saat reservasi restoran, pelanggan belum dapat memesan makanan dikarenakan tidak melihat menu yang tersedia di restoran saat melakukan reservasi di telepon. Reservasi juga dapat dilakukan langsung di restoran. Pemesanan makanan dan pembayaran tetap dilakukan di restoran.

Kini dengan teknologi informasi proses reservasi dapat dilakukan melalui aplikasi android. Aplikasi ini membantu pelanggan untuk melalukan resevasi, pemesanan makanan dan pembayaran dimanapun dan kapanpun. Pelanggan hanya perlu menunjukkan bukti reservasi saat datang ke restoran. Bukti reservasi tersebut dapat berupa nota transaksi ataupun bentuk lainnya yang berpa kode seperti barcode dan QR code.

Barcode merupakan kumpulan data optik yang dibaca mesin. Barcode berupa data dari lebar garis dan spasi garis paralel atau biasa disebut kode batang [1]. Barcode digunakan sebagai sarana untuk menginputkan data secara otomatis dengan membaca kode tersebut. Penggunaan barcode kini telah menyebar karena biayanya yang murah. Barcode dibaca dengan menggunakan scanner atau barcode scanner.

Penelitian terdahulu Perancangan Sistem Reservasi Restoran secara Online Berbasis Raspberry Pi dan Android, yang dilakukan Endang P. Kusumah tahun 2017 menggunakan sistem reservasi melalui aplikasi android [2]. Pelanggan melakukan pembayaran melalui transfer dan mendapatkan QR code sebagai bukti reservasi. Pada setiap meja restoran terdapat QR code sensor yang dapat digunakan pelanggan untuk menverifikasi reservasinya. Namun, penyediaan QR code sensor pada setiap meja tentulah membutuhkan sumber dana yang cukup banyak. Pada peneltian ini, sistem reservasi menghasilkan barcode. Barcode sensor hanya akan disediakan di pintu masuk restoran.

\section{KAJIAN PUSTAKA}

\subsection{Sistem Informasi Resevasi}

Sistem adalah suatu kesatuan yang terdiri atas komponen-komponen maupun prosedurprosedur yang saling bekerja sama untuk mencapai tujuan, yaitu mengalirkan sebuah informasi untuk mempermudah tercapainya sebuah tujuan perusahaan [3]. Reservasi 
memiliki makna sebuah proses untuk memesan benda ataupun tempat kepada orang lain Oleh karena itu dibuatlah sebuah sistem informasi reservasi secara online yang dapat mempermudah pelanggan dalam melakukan reservasi tanpa langsung datang ke restoran tersebut.

\subsection{Sistem Reservasi Online}

Pada saat reservasi restoran dan pencarian tempat kerja,kita tidak harus berada di tempat tersebut. Melainkan memanfaatkan kemajuan teknologi berupa internet. Dengan cara mengunduh sebuah aplikasi android pada smartphone. Sistem resevasi restoran serta pembukaan lapak kerja secara online ini akan dibuat dengan beberapa komponen hardware dan software [3].

\subsection{Web Server}

Web server adalah sebuah software yang memberikan layanan berbasis data dan berfungsi menerima permintaan dari HTTP atau HTTPS pada klien Web server menunggu permintaan dari client yang menggunakan browser seperti Netscape Navigator, Internet Explorer, Modzilla, dan program browser lainnya. Jika ada permintaan dari browser, maka web server akan memproses permintaan itu kemudian memberikan hasil prosesnya berupa data yang diinginkan kembali ke browser. Data ini mempunyai format yang standar, disebut dengan format SGML (standard general markup language). Data yang berupa format ini kemudian akan ditampilkan oleh browser sesuai dengan kemampuan browser tersebut [4].

\subsection{PHP}

PHP merupakan script yang menyatu dengan HTML dan berada pada server (server side HTML embedded scripting). Dengan menggunakan bahasa pemograman PHP ini bisa membuat beragam aplikasi berbasis web, mulai dari halaman web yang sederhana sampai aplikasi komplek yang membutuhkan koneksi ke database [5].

PHP (Hypertext Preprocessor), merupakan bahasa pemrograman web bersifat serverside, artinya bahasa berbentuk script yang disimpan dan dijalankan di komputer server (WebServer) sedang hasilnya yang dikirimkan ke komputer client (Web Browser)dalam bentuk script HTML (Hypertext Mark up Language) [5].

\subsection{Basic4Android}

Basic4Android adalah development tool sederhana yang powerful untuk membangun aplikasi Android. Bahasa Basic4Android mirip dengan bahasa Visual Basic dengan tambahan dukungan untuk objek. Aplikasi Android (APK) yang dicompile oleh Basic4Android adalah aplikasi Android native/asli dan tidak ada extra runtime seperti di Visual Basic yang ketergantungan file msvbvm60.dll, yang pasti aplikasi yang dicompile oleh Basic4Android adalah No Dependencies (tidak ketergantungan file oleh lain).

IDE Basic4Android hanya fokus pada development Android. Basic4Android termasuk designer GUI untuk aplikasi Android yang powerful dengan dukungan Built-in untuk multiple screens dan orientations, serta tidak dibutuhkan lagi penulisan XML yang rumit. Basic4adnroid kaya akan satuan libraries yang membuatnya lebih mudah untuk mengembangkan aplikasi Android [6]. 


\section{METODE PENELITIAN}

Metode pendekatan terstruktur. Metode pengembangan waterfall. Langkah-langkah waterfall ialah analisis kebutuhan, desain sistem, implementasi, pengujian dan pemeliharaan.

\section{HASIL DAN PEMBAHASAN}

Penelitian ini untuk memudahkan pelanggan dalam melakukan reservasi dan pemesanan makanan pada restoran melalui aplikasi android. Pelanggan akan mendapatkan barcode sebagai bukti reservasi. Barcode ditunjukkan saat pelanggan datang dan ini akan mempersingkat waktu dalam menunggu makanan tersaji. Penelitian terdahulu mengenai reservasi restoran [2], menggunakan QR code dengan menyediakan QR code scanner di setiap meja restoran.

Diagram konteks sistem renovasi restoran yang diusulkan seperti terlihat pada gambar 2 . Entitas luar yang terlibat hanyalah pelanggan. Input yang pelangan berikan pada sistem adalah data pelanggan, data reservasi, data pesanan makanan, barcode dan data konfirmasi pembayaran. Output yang diberikan sistem pada pelanggan, yaitu data menu, data meja, data pembayaran, data reservasi valid dan barcode.

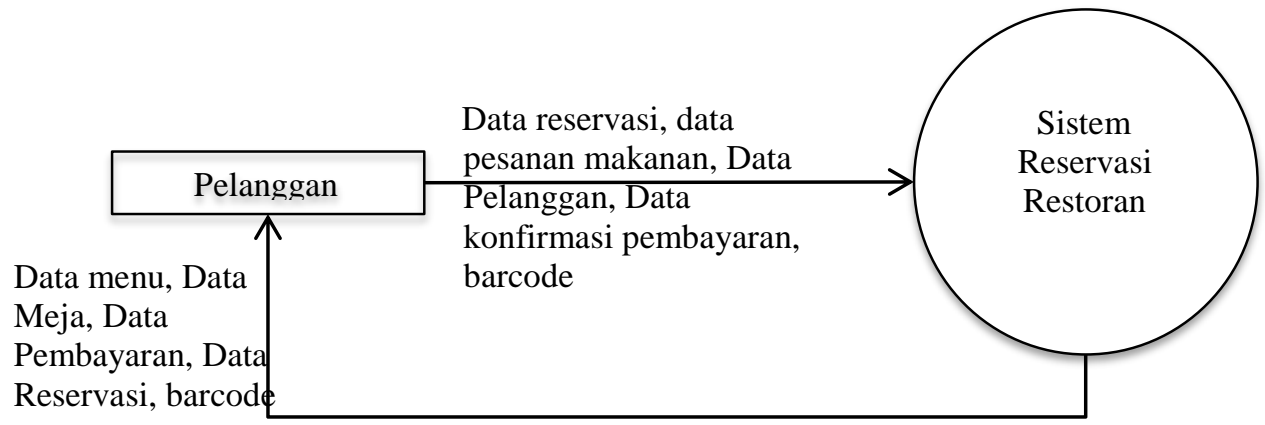

Gambar 2. Diagram Konteks Sistem Reservasi Restoran

Proses pada sistem reservasi restoran kemudian dibagi menjadi dua proses (proses reservasi dan pembayaran) seperti pada gambar 3. 


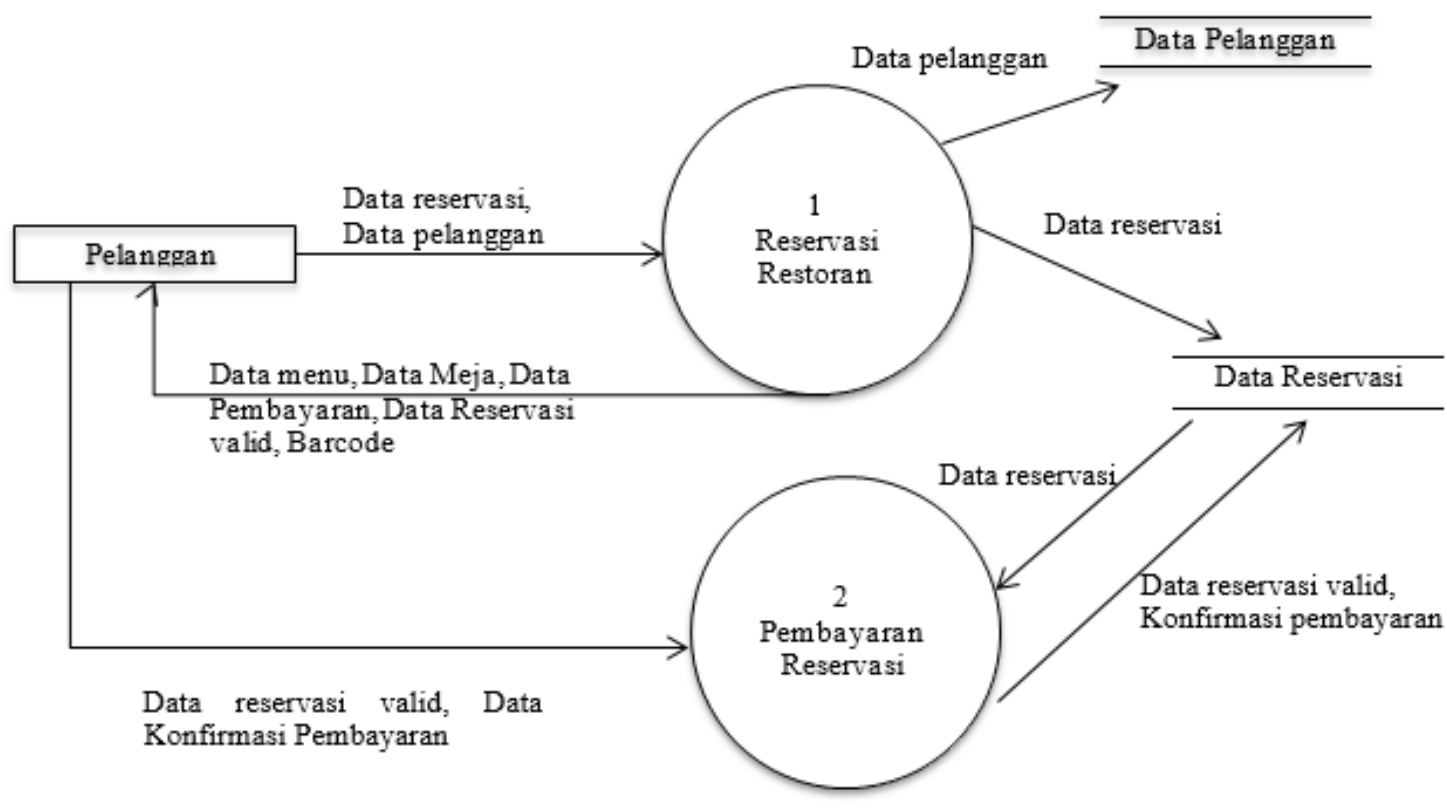

Gambar 3. DFD Sistem Reservasi Restoran

Pada proses 1, pelanggan melakukan reservasi dengan memesan meja dan menu makanan. Selanjutnya, jika reservasi berhasil maka akan diverifikasi admin. Admin akan mengirimkan barcode pada pelanggan. Barcode inilah yang nanti akan dipindai sebagai bukti revervasi di restoran. Pelanggan melakukan pembayaran dan konfirmasi pembayaran pada proses 2 .

\subsection{Hasil Pengujian}

Pengujian software yang dilakukan menggunakan metode black box testing, yaitu untuk menguji fungsionalitas sistem, apakah sistem berjalan dengan baik dan menghasilkan output sesuai dengan fungsinya. Pengujian dilakukan pada proses resgitrasi, transaksi pemesanan, dan verifikasi pembayaran.

\section{a. Pada pengujian proses registrasi}

Pengujian dilakukan untuk mengetahui apakah sistem database pada server mampu untuk menyimpan data pelanggan pada saat pendaftaran akun baru apakah dapat berfungsi dengan baik dalam menyimpan data baru ke server.
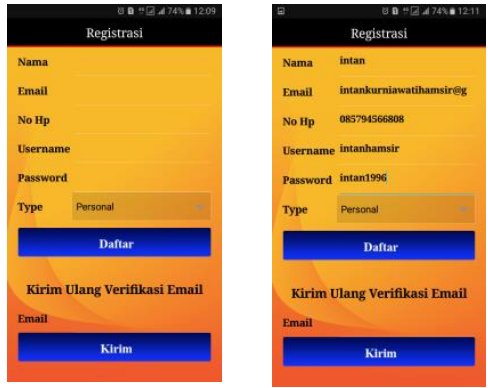

Gambar 4. Proses registrasi personal 
Pengujian yang dilakukan berupa pengujian pengisian data nama, e-mail, no.hp, username, password dan type pendaftaran seperti terlibat pada tabel 1 .

Tabel 1 pengujian proses registrasi personal

\begin{tabular}{|l|l|l|l|}
\hline No & Nama & keterangan & $\begin{array}{l}\text { Persentase } \\
\%\end{array}$ \\
\hline 1 & Intanhamsir & Berhasil ditambahkan & $90 \%$ \\
\hline 2 & hamsir & Berhasil ditambahkan & $90 \%$ \\
\hline 3 & tuti & Berhasil ditambahkan & $90 \%$ \\
\hline 4 & adi & Berhasil ditambahkan & $90 \%$ \\
\hline 5 & riyan & Berhasil ditambahkan & $90 \%$ \\
\hline \multicolumn{2}{|l|}{ Nilai rata-rata presentase keberhasilan } & $90 \%$ \\
\hline
\end{tabular}

\section{b. Pengujian transaksi pemesanan}

Pada pengujian transaksi pemesanan, pengujian dilakukan dengan cara login terlebih dahulu selanjutnya melakukan pemesanan meja, makanan atau minuman, kemudian mengisi form pemesanan. pada tabel 2 telah dilakukan pengujian sebanyak 5 kali dengan member yang berbeda sebagai berikut:
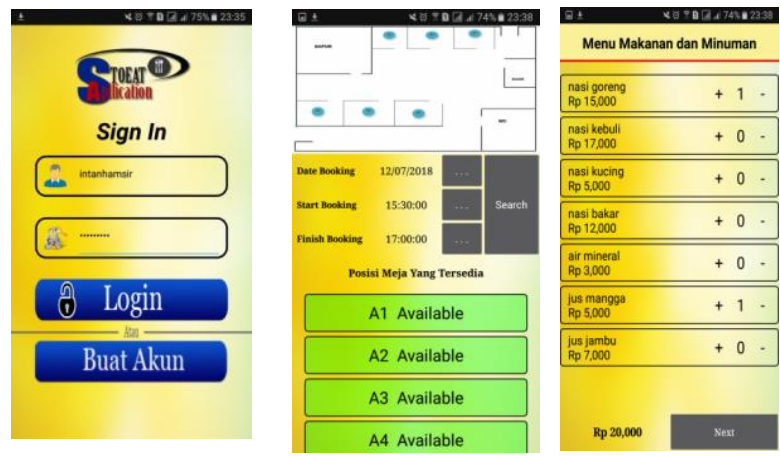

Gambar 5. Proses pengujian reservasi meja

Pengujian transaksi pemesanan dilakukan sebanyak lima kali dengan user yang berbeda seperti pada tabel 2 .

Tabel 2. Pengujian transaksi pemesanan

\begin{tabular}{|l|l|l|l|l|l|}
\hline No & Nama & Meja & Makanan & Keterangan & $\%$ \\
\hline 1 & intanhamsir & A1 & Nasi goreng & Berhasil & 95 \\
\hline 2 & hamsir & A2 & Ikan bakar & Berhasil & 95 \\
\hline 3 & tuti & A3 & Ayam bakar & Berhasil & 95 \\
\hline 4 & riyan & A4 & Jus alpukat & Berhasil & 95 \\
\hline 5 & adi & A5 & Nasi kebuli & berhasil & 95 \\
\hline \multicolumn{5}{|l}{ Presentase keberhasilan rata -rata } & 95 \\
\hline
\end{tabular}

\section{c. Pengujian transaksi verifikasi pembayaran}

Pada pengujian transaksi pembayaran, jika pelanggan telah melakukan pembayaran, maka admin akan mengecek saldo rekening restoran tersebut, dan dilakukan proses verifikasi, 
dengan cara pelanggan menguplod bukti transaksi kemudian jika admin merubah status pemesanan menjadi ok. Maka pelanggan akan mendapatkan Barcode.

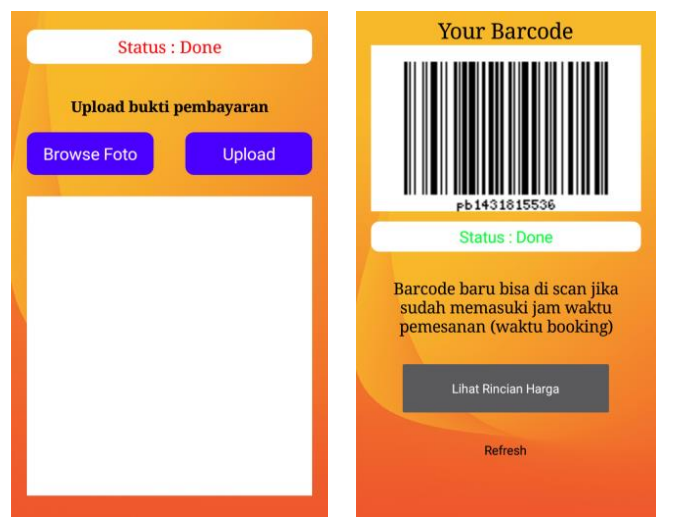

Gambar 6. Proses verifikasi pembayaran

Pada tabel 3 dilakukan pengujian sebanyak 5 kali pada orang yang berbeda.

Tabel 3. Pengujian verifikasi pembayaran

\begin{tabular}{|l|l|l|l|l|}
\hline No & Nama & Status & keterangan & $\%$ \\
\hline 1 & intanhamsir & Ok & Mendapatkan Barcode & 95 \\
\hline 2 & hamsir & Ok & Mendapatkan Barcode & 95 \\
\hline 3 & tuti & Ok & Mendapatkan Barcode & 95 \\
\hline 4 & adi & Ok & Mendapatkan Barcode & 95 \\
\hline 5 & riyan & Ok & Mendapatkan Barcode & 95 \\
\hline \multicolumn{4}{|l}{ Presentase keberhasilan rata-rata } & $95 \%$ \\
\hline
\end{tabular}

\section{d. Pengujian perangkat keras}

Pada pengujian perangkat ini terdiri atas pengujian scanner, pengujian perubahan display, serta pengujian sensor ultrasonic.

\section{e. Pengujian barcode reader}

Pada pengujian ini, setelah pelanggan menerima barcode pada tahap sebelumnya. Pelanggan datang ke restoran tersebut kemudian memindai barcode tersebut menggunakan Barcode reader. Berikut merupakan hasil pengujian dapat dilihat pada tabel 4.

Tabel 4 Pegujian barcode

\begin{tabular}{|l|l|l|l|}
\hline No & Pemesanan & keterangan & $\%$ \\
\hline 1 & intanhamsir & Barcode terbaca & 100 \\
\hline 2 & hamsir & Barcode terbaca & 100 \\
\hline 3 & tuti & Barcode terbaca & 100 \\
\hline 4 & adi & Barcode terbaca & 100 \\
\hline 5 & riyan & Barcode terbaca & 100 \\
\hline Presentase keberhasilan rata-rata & $100 \%$ \\
\hline
\end{tabular}

\section{f. Pengujian perubahan pada display dot-matrix}


Perubahan pada dot matrix akan terjadi saat status pemesanan ok, kemudian setelah Barcode terbaca dan cocok, kemudian saat sensor ultrasonic tidak mendeteksi adanya orang.

Tabel 5 Pengujian perubahan pada display dotmarix

\begin{tabular}{|l|l|l|}
\hline Pemesanan & keterangan & $\%$ \\
\hline 1 & Display berubah menjadi welcome & 100 \\
\hline 2 & Display berubah menjadi welcome & 100 \\
\hline 3 & Display berubah menjadi welcome & 100 \\
\hline 4 & Display berubah menjadi welcome & 100 \\
\hline 5 & Display berubah menjadi welcome & 100 \\
\hline \multicolumn{2}{|l|}{ Presentase keberhasilan rata-rata } & 100 \\
\hline
\end{tabular}

\section{g. Pengujian sensor HC-SR04}

Pada pengujian sensor ultrasonic ini, Selama sensor ini masih mendeteksi adanya orang maka tulisan pada display masih sama. Namun jika dalam kurun waktu 10 menit tidak di terdeteksi adanya orang maka akan terjadi perubahan status.

Tabel 6 pengujian sensor ultrasonic HC-SR04

\begin{tabular}{|l|l|l|l|l|}
\hline no & Time & Keterangan & Perubahan pada display & $\%$ \\
\hline 1 & 5 menit & Ada objek & Tetap & 100 \\
\hline 2 & 7 menit & Ada objek & Tetap & 100 \\
\hline 3 & 8 menit & Ada objek & Tetap & 100 \\
\hline 4 & 13 menit & Tidak ada objek & Berubah & 100 \\
\hline 5 & 15 menit & Tidak ada objek & Berubah & 100 \\
\hline 6 & 18 menit & Tidak ada objek & Berubah & 100 \\
\hline \multicolumn{4}{|l|}{ Presentase keberhasilan rata-rata } & 100 \\
\hline
\end{tabular}

\section{KESIMPULAN}

Sistem reservasi restoran dapat membantu pelanggan melakukan reservasi restoran melalui android kapanpun dan dimanapun. Dengan aplikasi android, pelanggan dapat melihat menu yang tersedia di restoran dan melakukan pemesanan bersamaan dengan reservasi restoran. Barcode yang diberikan sistem pada pelanggan setelah melakukan reservasi bisa digunakan untuk verifikasi saat datang ke restoran. Verifikasi dilakukan di pintu masuk restoran. Dengan begitu, pesanan akan segera di proses dan mempersingkat waktu tunggu pesanan. Berbeda halnya dengan penelitian terdahulu yang menyediakan $Q R$ code scanner di tiap meja, yang tentunya akan membutuhkan dana yang cukup banyak dalam penerapannya.

\section{DAFTAR PUSTAKA}

[1] Ir. Sere Saghranie Daulay, M.Si. "Hubungan Barcode dengan Produk Industri Sebagai Standar Perdagangan Produk Masa Kini”, KEMENPERIN.

[2] Mochamad Fajar Wicaksono. 2017. "Implementasi Modul Wifi Nodemcu Esp8266 Untuk Smart Home”, Jurnal Komputika Jurusan Teknik. Komputer UNIKOM, Vol. 6 No. 1, p. 1-6.

[3] https://www.zonareferensi.com/pengertian-sistem/

[4] Upton, E. 2012. Raspberry Pi 3 Guide 
[5] Khairil 2012. MODUL1 Pengantar PHP dan Web Server

[6] http://mk.elektro.ub.ac.id/tutorial-install-ide-b4a/ 